\title{
Emendation of the Description of Acidaminococcus fermentans, a trans-Aconitate- and Citrate-Oxidizing Bacterium
}

\author{
GREGORY M. COOK, ${ }^{1}$ FREDERICK A. RAINEY, ${ }^{2}$ GUANGJIONG CHEN, ${ }^{3}$ ERKO STACKEBRANDT, ${ }^{2}$ \\ AND JAMES B. RUSSELL ${ }^{1,4 *}$ \\ Section of Microbiology ${ }^{1}$ and Department of Animal Science, ${ }^{3}$ Cornell University, Ithaca, New York 14853; German \\ Collection of Microorganisms and Cell Cultures, Braunschweig, Germany ${ }^{2}$; and Agricultural Research Service,
} U.S. Department of Agriculture, Ithaca, New York $14850^{4}$

\begin{abstract}
Ruminal fluid which was enriched with trans-aconitate yielded a gram-negative diplococcus (strain AO) which was identified by $16 \mathrm{~S}$ ribosomal DNA sequence analysis as Acidaminococcus fermentans. In contrast to the original description, the $A$. fermentans type strain and strain AO were found to utilize citrate as an energy source and to produce hydrogen and hydrogen sulfide. The descriptions of the genus and species are emended accordingly.
\end{abstract}

Grass tetany, a potentially fatal magnesium deficiency disease of ruminants, has been correlated with the accumulation of trans-aconitate in plants $(1,3)$. Recent work has revealed that ruminal bacteria reduce trans-aconitate to tricarballylate (15-18). This nonmetabolizable tricarboxylic acid chelates blood magnesium and increases excretion of this element (19). Mixed-culture studies revealed that some of the trans-aconitate can also be converted to acetate, a nontoxic end product, but trans-aconitate-oxidizing bacteria were not isolated in these studies $(15,16,18)$.

When ruminal contents from a cow fed grass hay were transferred successively in a medium containing $10 \mathrm{mM}$ transaconitate and $100 \mathrm{mM}$ sodium (4), high-pressure liquid chromatography (HPLC) revealed (7) that more than $60 \%$ of the trans-aconitate was oxidized. The trans-aconitate enrichment preparations used produced four colony types on $2 \%$ agar at $39^{\circ} \mathrm{C}$ in an anaerobic glove box (Coy Manufacturing Co., Ann Arbor, Mich.), but only the large, circular, white colonies utilized trans-aconitate $(10 \mathrm{mM})$ as an energy source for growth. Five trans-aconitate-utilizing strains were isolated initially, but all of these nonmotile, nonsporulating bacteria had the same cell morphology (they were diplococci) and Gram staining characteristics (they were gram negative).

Strain AO did not produce indole, and gelatin hydrolysis was virtually undetectable. Strain AO utilized citrate, glutamate, and pyruvate (Table 1). No growth was observed in the presence of glucose, maltose, sucrose, cellobiose, xylose, arabinose, ribose, lactate, oxaloacetate, malate, fumarate, or succinate. Strain AO could not grow aerobically. Growth was observed at 39 or $45^{\circ} \mathrm{C}$ but not at 25 or $50^{\circ} \mathrm{C}$. Acetate was always the predominant fermentation end product, but butyrate was also detected, particularly when glutamate was the energy source (Table 1). Hydrogen gas (as detected with a Gow-Mac model 550 thermal conductivity gas chromatograph equipped with a Supelco S-8100 column) was also an end product of trans-aconitate or citrate fermentation. When glutamate was the energy source, ammonia (6) was produced. Tricarballylate was never detected. Strain AO produced hydrogen sulfide (ferrous sulfate precipitated as ferrous sulfide). Ammonia could not be utilized as a sole nitrogen source, and the bacterium grew slowly (specific growth rate, $0.05 \mathrm{~h}^{-1}$ )

${ }^{*}$ Corresponding author. Mailing address: Cornell University, Wing Hall, Ithaca, NY 14853. Phone: (607) 255-4508. Fax: (607) 255-3904. when the Trypticase concentration was less than $1 \mathrm{mg} / \mathrm{ml}$ and no other energy source was provided.

On the basis of the results described above, it appeared that strain AO might belong to the genus Acidaminococcus (nonsporulating, nonmotile, anaerobic, gram-negative diplococci), but Acidaminococcus fermentans, the only species currently recognized, was described as a bacterium which (i) could not utilize citrate or pyruvate as an energy source, (ii) was completely suppressed by pyruvate, and (iii) could not produce hydrogen or hydrogen sulfide $(13,14)$. Since strain AO grew rapidly (specific growth rate, $0.3 \mathrm{~h}^{-1}$ ) in the presence of citrate and fairly rapidly in the presence of pyruvate (specific growth rate, $0.14 \mathrm{~h}^{-1}$ ), produced large amounts of sulfide, and produced hydrogen gas as an end product, the phylogenetic position of strain AO was in question.

Direct comparisons between strain AO and strain ATCC 25085 , the type strain of $A$. fermentans, revealed (i) that both strains utilized trans-aconitate, citrate, and glutamate as energy sources and that the growth rates obtained with these substrates were similar, (ii) that both strains produced hydrogen gas when either citrate or trans-aconitate was the energy source, (iii) that both strains produced small amounts of hydrogen gas from glutamate, and (iv) that both strains produced hydrogen sulfide when cysteine was used as a reducing agent $(0.6 \mathrm{mg}$ of cysteine hydrochloride per $\mathrm{ml}$ ). Strain ATCC $25085^{\mathrm{T}}$ ( $\mathrm{T}=$ type strain) did not readily grow on pyruvate in our studies, but other workers have found that this organism can ferment pyruvate under the correct cultural conditions (8). The $\mathrm{G}+\mathrm{C}$ content of the DNA of strain AO was $54.7 \mathrm{~mol} \%$ (as determined by the HPLC method), while the $\mathrm{G}+\mathrm{C}$ content determined previously for $A$. fermentans ATCC $25085^{\mathrm{T}}$ was $56.6 \mathrm{~mol} \%$ (as determined by the buoyant density method). On the basis of these results, it appeared that strain $\mathrm{AO}$ and strain ATCC $25085^{\mathrm{T}}$ were virtually identical.

Strain AO could not utilize either trans-aconitate or citrate as an energy source if sodium salts were omitted from the basal medium $(<0.1 \mathrm{mM}$ sodium $)$, but it grew rapidly in the presence of trans-aconitate if $1 \mathrm{mM}$ sodium was added. Rapid growth on citrate was not observed until the sodium concentration was greater than $10 \mathrm{mM}$. Because the medium used by Rogosa (13) to characterize $A$. fermentans contained more than $20 \mathrm{mM}$ sodium, the contradiction regarding citrate utilization cannot be readily explained. On the basis of our results, the statement that $A$. fermentans cannot utilize citrate is not correct.

When the $16 \mathrm{~S}$ ribosomal DNAs of strain $\mathrm{AO}$ and $A$. 
TABLE 1. Comparison of strains AO and ATCC $25085^{\mathrm{T}}$

\begin{tabular}{|c|c|c|c|c|c|c|c|c|}
\hline \multirow{2}{*}{ Growth substrate } & \multicolumn{2}{|c|}{$\begin{array}{l}\text { Maximum specific growth } \\
\text { rate }\left(\mathrm{h}^{-1}\right)\end{array}$} & \multicolumn{2}{|c|}{$\begin{array}{l}\text { Acetate concn }(\mathrm{mmol} / \mathrm{mmol} \\
\text { of substrate) }\end{array}$} & \multicolumn{2}{|c|}{$\begin{array}{l}\text { Butyrate concn (mmol/mmol } \\
\text { of substrate) }\end{array}$} & \multicolumn{2}{|c|}{$\begin{array}{l}\text { Hydrogen gas concn (mmol/ } \\
\text { mmol of substrate) }\end{array}$} \\
\hline & Strain AO & $\begin{array}{c}\text { Strain } \\
\text { ATCC } 25085^{\mathrm{T}}\end{array}$ & Strain AO & $\begin{array}{c}\text { Strain } \\
\text { ATCC } 25085^{\mathrm{T}}\end{array}$ & Strain $\mathrm{AO}$ & $\frac{\text { Strain }}{\text { ATCC } 25085^{\mathrm{T}}}$ & Strain AO & $\begin{array}{c}\text { Strain } \\
\text { ATCC } 25085^{\mathrm{T}}\end{array}$ \\
\hline trans-Aconitate & 0.62 & 0.60 & 1.8 & 1.9 & 0.1 & 0.1 & 0.5 & 0.5 \\
\hline Citrate & 0.30 & 0.28 & 1.9 & 2.0 & 0.1 & 0.1 & 0.7 & 0.6 \\
\hline Glutamate & 0.31 & 0.35 & 1.1 & 1.1 & 0.3 & 0.4 & $<0.1$ & $<0.005$ \\
\hline Pyruvate & 0.14 & $\mathrm{NG}^{a}$ & 1.0 & NG & & & & \\
\hline
\end{tabular}

${ }^{a}$ NG, no growth detected.

fermentans DSM $20731^{\mathrm{T}}\left(=\right.$ ATCC $25085^{\mathrm{T}}$ ) were amplified by a PCR and sequenced as described previously $(11,12)$, a comparison of nearly complete $16 \mathrm{~S}$ ribosomal DNA sequences (1,507 bases) revealed that strain AO exhibited $100 \%$ homology with strain ATCC $25085^{\mathrm{T}}$. These $16 \mathrm{~S}$ ribosomal DNA sequences are now available in the EMBL data base under accession numbers X77951 and X78017. On the basis of these results, it appeared that strain $\mathrm{AO}$ should be classified as an $A$. fermentans strain. The phylogenetic position of $A$. fermentans within the radiation of the gram-positive bacteria belonging to the Clostridium-Bacillus subphylum has been described previously (2).

$A$. fermentans was isolated previously from the intestinal tracts of pigs and humans $(13,14)$, but not from the rumen. When ruminal fluid was obtained from a cow fed grass hay containing $11.1 \%$ crude protein, $69.1 \%$ neutral detergent fiber, $47.1 \%$ acid detergent fiber, $0.24 \%$ magnesium, and $0.78 \%$ calcium on a dry matter basis and was diluted 10 -fold $(n=3)$ in a medium containing mixed carbohydrates (4), the most probable number of carbohydrate-fermenting bacteria was 0.6 $\times 10^{9}$ bacteria. When $10 \mathrm{mM}$ trans-aconitate was provided as the only energy source, growth was not observed at dilutions greater than $10^{2}$. The paucity of $A$. fermentans was probably related to the lack of trans-aconitate, citrate, or pyruvate in the grass hay that was fed to the cow. The hay did contain the amino acid glutamate, another potential energy source of $A$. fermentans (Table 1), but this amino acid is rapidly deaminated by a variety of ruminal bacteria (5). The $\mathrm{pH}$ of the ruminal fluid was 6.7 , and strain $\mathrm{AO}$ is a fairly acid-resistant bacterium (Fig. 1).

Since trans-aconitate accumulation in plants is a transient and sudden event that is observed only in grazing situations (9,

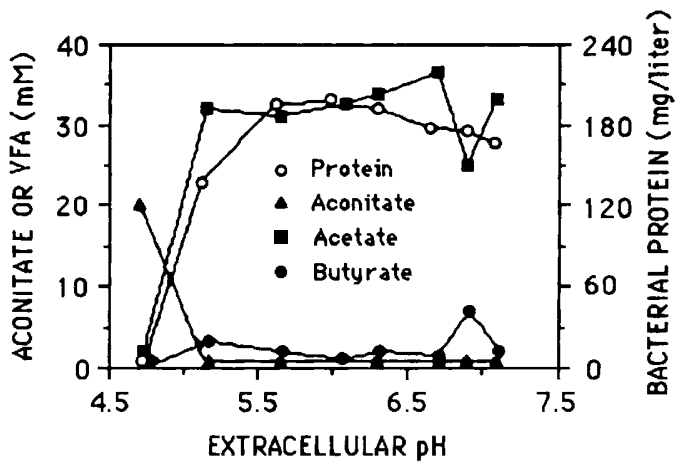

FIG. 1. Effect of extracellular $\mathrm{pH}$ on the growth of strain $\mathrm{AO}$ in a continuous culture (specific growth rate, $0.1 \mathrm{~h}^{-1}$ ) when trans-aconitate was used as an energy source and on the production of volatile fatty acids (VFA). The $\mathrm{pH}$ was decreased by adding concentrated $\mathrm{HCl}$ to the medium reservoir.
10) and commercial trans-aconitate is expensive, it was not possible for us to feed the cow a diet which contained trans-aconitate. Additional work will be needed to assess the ability of $A$. fermentans to counteract tricarballylate accumulation. If there is insufficient time for $A$. fermentans ruminal numbers to increase, ruminal inoculation may be a way to prevent tricarballylate-induced hypomagnesemia.

On the basis of the results obtained in this study, emended descriptions of the genus Acidaminococcus and the species $A$. fermentans are given below. It was necessary to emend both the genus description and the species description because of metabolic characteristics which should now be considered species characteristics. The descriptions are for the most part based on the descriptions given previously $(13,14)$.

Description of the genus Acidaminococcus. Acidaminococcus (Rogosa, 1969, 765) emend. Cook, Rainey, Chen, Stackebrandt, and Russell 1994 (A. cid. a. min. o. coc' cus. M. L. n. acidum, acid; M. L. adj. amino; Gr. n. coccus, a grain, berry; M.L. masc. n. Acaminococcus, amino acid coccus). Cells are gram-negative, nonsporulating, nonmotile, cocci that are 0.6 to $1.0 \mu \mathrm{m}$ in diameter and often occur as oval or kidney-shaped diplococci. The cell wall contains meso-diaminopimelic acid; whole cells contain galactose, glucose, and ribose. Menaquinones and ubiquinones are absent. Chemoorganotrophic anaerobe. No growth occurs on the surfaces of solid media incubated in the presence of air. Temperature optimum, 30 to $37^{\circ} \mathrm{C}$. Weak or no growth occurs at 25 and $45^{\circ} \mathrm{C}$. Cells are not viable after heat treatment for $30 \mathrm{~min}$ at $60^{\circ} \mathrm{C}$. The optimum $\mathrm{pH}$ for growth is 7.0, and growth occurs in the $\mathrm{pH}$ range from 6.2 to 7.5. No serological cross-reactions occur between $\mathrm{Aci}$ daminococcus strains and either Veillonella serovars or Peptococcus aerogenes. The $\mathrm{G}+\mathrm{C}$ contents of the DNAs range from 54.7 to $57.4 \mathrm{~mol} \%$. Phylogenetically, this genus is a member of the Spormusa cluster (i.e., the cluster containing the genera Spormusa, Megasphaera, Selenomonas, Butyrivibrio, Pectinatus, and Zymophilus) and is a distinct lineage within the radiation of the Clostridium-Bacillus group. The type species is Acidaminococcus fermentans.

Description of Acidaminococcus fermentans. Acidaminococcus fermentans (Rogosa, 1969, 765) emend. Cook, Rainey, Chen, Stackebrandt, and Russell 1994 (fer. men' tans. M. L. part. adj. fementans, fermenting). The characteristics are the same as those described above for the genus. Additional characteristics are as follows. Glutamate, citrate, and transaconitate are used as sole energy sources for growth as long as sodium is present, and the end products of metabolism are acetate, butyrate, and hydrogen gas. Pyruvate is utilized by some strains. About $40 \%$ of the strains weakly metabolize glucose. Extremely weak or no growth occurs with cellobiose, lactose, melibiose, rhamnose, ribose, and fucose. Adonitol, esculin, amygdalin, arabinose, dulcitol, erythritol, erythrose, fructose, fumarate, galactose, glycerol, inositol, inulin, lactate, 
malate, maltose, mannitol, mannose, melibiose, $\alpha$-methyl-Dglucoside, $\alpha$-methyl-D-mannoside, raffinose, salicin, sorbitol, sorbose, succinate, sucrose, trehalose, and xylose are not utilized as energy sources.

Arginine, glutamic acid, tryptophan, and valine are required for growth; in addition, cysteine and histidine are required by $93 \%$ of the strains, phenylalanine and serine are required by $50 \%$ of the strains, and tyrosine is required by $79 \%$ of the strains. Glycine sometimes stimulates growth, while alanine, aspartic acid, isoleucine, leucine, lysine, methionine, proline, and threonine are not required for growth. In amino acidcontaining media, no growth occurs in the absence of biotin, pantothenate, pyridoxal, and vitamin $\mathrm{B}_{12} ; p$-aminobenzoic acid is essential or highly stimulatory for growth. Exogenous putrescine, folic acid, folinic acid, niacin, riboflavin, and thiamine are not required for growth. Benzidine, catalase, cytochrome oxidase, indole, and nitrate reduction tests are negative. $\mathrm{H}_{2} \mathrm{~S}$ is produced in cysteine-reduced media. Ammonia is produced. Sulfonthalein indicators are not reduced. Gelatin is not normally liquefied, but slow or partial liquefication sometimes occurs. Resistant to vancomycin $(7.5 \mu \mathrm{g} / \mathrm{ml})$. Acidaminococcus fermentans strains have been isolated from the intestinal tracts of pigs and humans and from the cow rumen. The type strain is VR4 (= ATCC $25085=$ DSM 20731).

This research was supported by the U.S. Dairy Forage Research Center, Madison, Wis.

\section{REFERENCES}

1. Bohman, V. R., A. L. Lesperance, G. D. Harding, and D. L. Grunes. 1969. Induction of experimental tetany in cattle. J. Anim. Sci. 29:99-102.

2. Both, B., W. Buckel, R. Kroppenstedt, and E. Stackebrandt. 1992. Phylogenetic and chemotaxonomic characterization of Acidaminococcus fermentans. FEMS Microbiol. Lett. 97:7-12.

3. Burau, R., and P. R. Stout. 1965. trans-Aconitic acid in range grasses in early spring. Science 150:766-767.

4. Caldwell, D. R., and M. P. Bryant. 1966. Medium without rumen fluid for nonselective enumeration and isolation of rumen bacteria. Appl. Microbiol. 14:794-801.

5. Chalupa, W. 1976. Degradation of amino acids by the mixed rumen microbial population. J. Anim. Sci. 43:828-834.
6. Chaney, A. L., and E. P. Marbach. 1962. Modified reagents for determination of urea and ammonia. Clin. Chem. 8:130-132.

7. Ehrlich, G. G., D. F. Goerlitz, J. H. Bourell, G. V. Eisen, and E. M. Godsy. 1981. Liquid chromatographic procedure for fermentation product analysis in the identification of anaerobic bacteria. Appl. Environ. Microbiol. 42:878-885.

8. Holdeman, L. V., E. P. Cato, and W. E. C. Moore. 1977. Anaerobe laboratory manual, p. 18. Virginia Polytechnic Institute and State University Anaerobe Laboratory, Blacksburg.

9. Mayland, H. F., D. L. Grunes, and V. A. Lazar. 1976. Grass tetany hazard of cereal forages based upon chemical composition. Agron. J. 68:665-667.

10. Prior, R. L., D. L. Grunes, R. P. Patterson, F. W. Smith, H. F. Mayland, and W. Visek. 1973. Partition column chromatography for quantitating effects of fertilization on plant acids. J. Agric. Food Chem. 21:73-77.

11. Rainey, F. A., M. Dorsch, H. W. Morgan, and E. Stackebrandt. 1992. 16S rDNA analysis of Spirochaeta thermophila: its phylogenetic position and implications for the systematics of the order Spirochaetales. Syst. Appl. Microbiol. 15:197-202.

12. Rainey, F. A., and E. Stackebrandt. 1993. 16S rDNA analysis reveals phylogenetic diversity among the polysaccharolytic clostridia. FEMS Microbiol. Lett. 113:125-128.

13. Rogosa, M. 1969. Acidaminococcus gen. n., Acidaminococcus fermentans sp. n., anaerobic gram-negative diplococci using amino acids as the sole energy source for growth. J. Bacteriol. 98:756766.

14. Rogosa, M. 1984. Genus II. Acidaminococcus, p. 684. In N. R. Kreig and J. G. Holt (ed.), Bergey's manual of systematic bacteriology, vol. 1. The Williams and Wilkins Co., Baltimore.

15. Russell, J. B. 1985. Enrichment and isolation of rumen bacteria that reduce trans-aconitic acid to tricarballylic acid. Appl. Environ. Microbiol. 49:120-126.

16. Russell, J. B., and N. Forsberg. 1986. Production of tricarballylic acid by rumen microorganisms and its potential toxicity in ruminant tissue metabolism. Br. J. Nutr. 56:153-162.

17. Russell, J. B., and H. F. Mayland. 1986. Absorption of tricarballylic acid from the rumen of sheep and cattle fed forages containing trans-aconitic acid. J. Sci. Food Agric. 40:205-212.

18. Russell, J. B., and P. J. Van Soest. 1984. In vitro ruminal fermentation of organic acids common in forage. Appl. Environ. Microbiol. 47:155-159.

19. Schwartz, R., M. Topley, and J. B. Russell. 1988. Effect of tricarballylic acid, a nonmetabolizable rumen fermentation product, on $\mathrm{Mg}, \mathrm{Ca}$, and $\mathrm{Zn}$ utilization. J. Nutr. 118:183-188. 